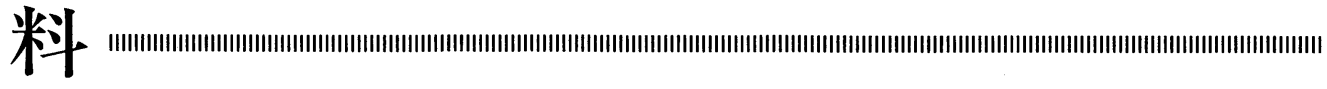

\title{
トレッド配合におけるカーボンと シリカの比較
}

小林 直 一*

1.は じめに

夕イヤに求められる性能として, 低燃費性, 安 全性, 耐摩耗性等がある.なかでも低燃費性と安 全性は一見二律背反の関係にあり，両立させるた めに多くの研究がなされている1).これらのラボ 指標として，一般に50〜 $70^{\circ} \mathrm{C} \tan \delta(10 \sim 20 \mathrm{~Hz})$ と $0{ }^{\circ} \mathrm{C} \tan \delta(10 \sim 20 \mathrm{~Hz})$ がそれぞれ使用されてい $ろ^{2)}$. 低燃費性の指標である50〜 70 $\mathrm{C} \tan \delta$ $(10 \sim 20 \mathrm{~Hz})$ は，実走中の夕イヤ温度と回転速度 から条件が定められているが, 安全性のラボ指標 である $0{ }^{\circ} \mathrm{C} \tan \delta(10 \sim 20 \mathrm{~Hz})$ は，時間温度換算則 の適用により決定された指標である。最近，夕イ ヤトレッド用の充てん剤としてカーボンブラック (CB)よりも低燃費性と安全性のバランスが良好 であるシリカが注目されている ${ }^{3,4)}$. そこで，シ リカ配合ゴムをラボで評価するために は，CB 配合ゴムでのこれらラボ指標 がシリカ配合ゴムにも適用できるかど うかを確認する必要がある。本研究で は，シリカ配合ゴムの燃費性と安全性 のラボ指標の開発と, シリカ配合にお けるスチレンーブタジエン共重合体ゴ ム $(\mathrm{SBR}) の ミ ク ロ$ 構造等の燃費性, 安全性に対する影響の解明を目指した
見極めるために, $\tan \delta$ の時間温度換算によるシ フトファクター $\log \mathrm{a}_{\mathrm{T}}$ の温度依存性について以 下の因子の影響を検討した。

1) $\mathrm{CB}$ とシリカの違い

2）フィラー充てん量

3 ) SBR のミクロ構造

4) オイル量

シフトファクターを求める際には動的弾性率〜周 波数 $\left(\mathrm{G}^{\prime}(\boldsymbol{\omega})\right)$ 曲線あるいは損失弾性率〜周波数 $(G ”(\omega))$ 曲線が用いられることもある。しかし 一般に，損失正接 $\tan \delta\left(\equiv \mathrm{G}^{\prime \prime} / \mathrm{G}^{\prime}\right)$ は $\mathrm{G}$ あるいは G”よりも充てん剤による体積効果の影響を受け にくいと考えられる7). したがって，本研究では デー夕解析の精度を上げるために， $\tan \delta 〜 \omega$ 曲 線の時間温度換算より $\log \mathrm{a}_{\mathrm{T}}$ の温度依存性を求 めた. その際, $\tan \delta$ 温度分散曲線におけるピー

表 1 SBR の分子特性

\begin{tabular}{llccccc}
\hline & 変性剂 & $\begin{array}{c}\text { ビニル量 } \\
(\%)\end{array}$ & $\begin{array}{c}\text { スチレン量 } \\
(\%)\end{array}$ & $\begin{array}{c}\text { 油展量 } \\
(\mathrm{phr})\end{array}$ & $\begin{array}{c}\mathrm{Tg} \\
\left({ }^{\circ} \mathrm{C}\right)\end{array}$ & $(\mathrm{OE}-) \mathrm{MV}^{* 1}$ \\
\hline $\mathrm{SBR}-\mathrm{A}$ & $\mathrm{SnCl}_{4}$ & 62 & 20 & 0 & -36 & 74 \\
$\mathrm{SBR}-\mathrm{B}$ & $\mathrm{SnCl}_{4}$ & 21 & 35 & 0 & -51 & 74 \\
$\mathrm{SBR}-\mathrm{C}$ & $\mathrm{SiCl}_{4}$ & 61 & 20 & 37.5 & -37 & 34 \\
$\# 1712$ & $\mathrm{None}_{12}$ & 19 & 23 & 37.5 & -56 & 47 \\
\hline
\end{tabular}

$* 1: 1+4,100^{\circ} \mathrm{C}$

ものである.第 46 回日本ゴム協会優秀論文賞の 対象論文のほか, 上記に関連する研究で明らかに した結果を加えさせていただく5).

\section{CBとシリカの比較}

\section{$2.1 \tan \delta$ の時間温度換算による比較 5,6$)$}

$\mathrm{CB}$ 配合物に用いられているタイヤ材料評価用 ラボ指標がシリカ配合物にも適用可能かどうかを

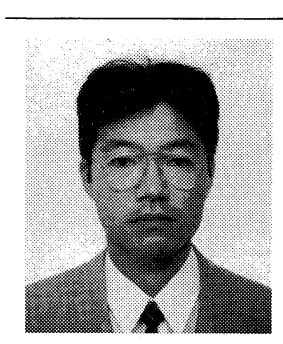

*JSR (侏)(干510-8552 三重県四日 市市川尻町100) 高分子研究所工ラ ストマー開発室第一チーム. 平成 3 年大阪府立大学大学院修士課程 応用化学科卒業. 同年, JSR 侏入 社, 現在に至る。

専門は, 汎用ゴムの評価および重 合. 
表 2 配合内容

\begin{tabular}{lcccccccccc}
\hline \multicolumn{1}{c}{ (phr) } & 1 & 2 & 3 & 4 & 5 & 6 & 7 & 8 & 9 & 10 \\
\hline SBR-A & 100 & 100 & & & & & & & 100 & \\
SBR-B & & & 100 & 100 & & & & & & \\
SBR-C & & & & & 137.5 & 137.5 & & & & 137.5 \\
\#1712 & & & & & & & 137.5 & 137.5 & & \\
CB (N330) & 43.2 & & 43.2 & & 75.6 & & 75.6 & & & \\
Silica (AQ) & & 40 & & 40 & & 70 & & 70 & & \\
X50S*1 & & 6.4 & & 6.4 & & 11.2 & & 11.2 & & \\
Nocceler DM & 1.5 & 1.2 & 1.5 & 1.2 & 1.5 & 1.2 & 1.5 & 1.2 & 1.5 & 1.5 \\
Nocceler D & & 1.7 & & 1.7 & & 1.7 & & 1.7 & & \\
\hline
\end{tabular}

$\mathrm{ZnO} /$ Stearic Acid/6PPD/Sulfur=3/2/1/1.5

* 1 : X50S は, N330/ビス(トリエトキシシリルプロピル)テトラサルファン $=1 / 1$ の混合物

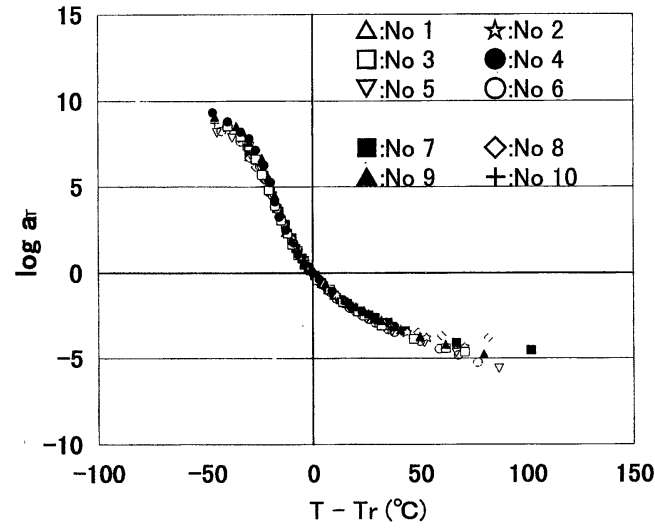

困 1 シフトファクター $\log \mathrm{a}_{\mathrm{r}}$ の温度依存性

ク温度 $\left(T_{\tan \delta, \max }\right)$ を基準温度 $(\mathrm{Tr})$ に選んだ。使 用したポリマーの特性を表 1 に，配合内容を表 2 に示す。その結果，上記因子の影響を受けること なく供試試料すべての $\log \mathrm{a}_{\mathrm{T}}$ の温度依存性が一 致することが分かった(図 1 ).

\section{2 ウエットグリップ等の比較 ${ }^{6)}$}

表 1 の SBR-A を用い，比較的低充てん(フィ ラー量 $45 \mathrm{phr}$ ) 配合でシリカと CB の此較を行っ た。ポータブルスキッドテスターに用いたアスフ アルトの温度と摩擦係数の関係を図 2 に示す。両 者配合ゴム試料の摩擦係数は, 測定温度領域にお いてほぼ一致している。これは Wolff 等による 実走夕イヤテストでのフィラー量同等のままシリ カ/CBの比率を変えた検討により，安全性は同 等であると報告されていることと一致する ${ }^{8)}$. ま

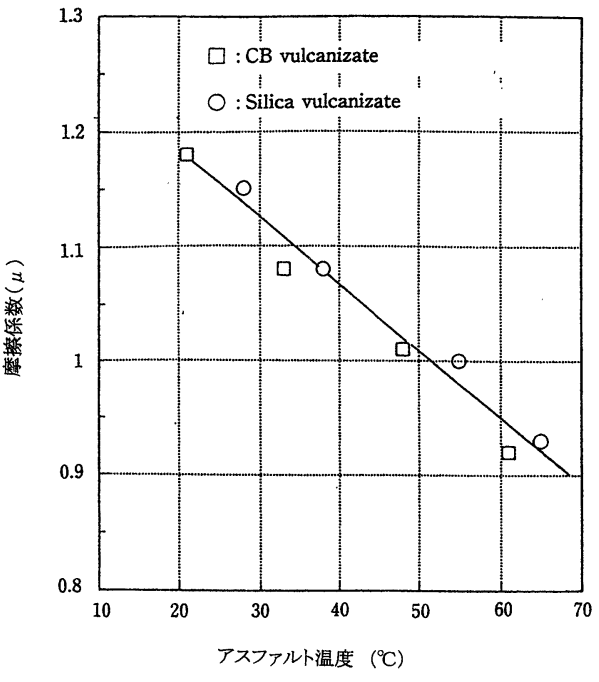

困 2 アスファルト温度と摩擦係数の関係

たシリカ配合ゴムと $\mathrm{CB}$ 配合ゴムの $0{ }^{\circ} \mathrm{C} \tan \delta(15$ $\mathrm{Hz})$ は，それぞれ 0.39 と 0.41 とほぼ一致する.

\section{3 燃費性の比較 ${ }^{6)}$}

シリカ配合ゴムと $\mathrm{CB}$ 配合ゴムの $50^{\circ} \mathrm{C} \tan \delta(15$

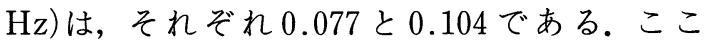
で, 走行時に夕イヤで発生する発熱量 $\mathrm{H}$ は線形 粘弾性理論によれば次式で表される。

$\mathrm{H} \propto \omega \mathrm{S}^{2} \mathrm{G}^{\prime} \tan \delta$

のは周波数， $\mathrm{S}$ はUずみを示す．実走条件では タイヤにかかる荷重は一定とみなしうる。図 3 に 両者配合ゴムの S-S 曲線を比較した結果を示す。 定荷重の場合, シリカ配合ゴムは CB 配合ゴムと 比較して, S-S 曲線から分かるようにUずみが 


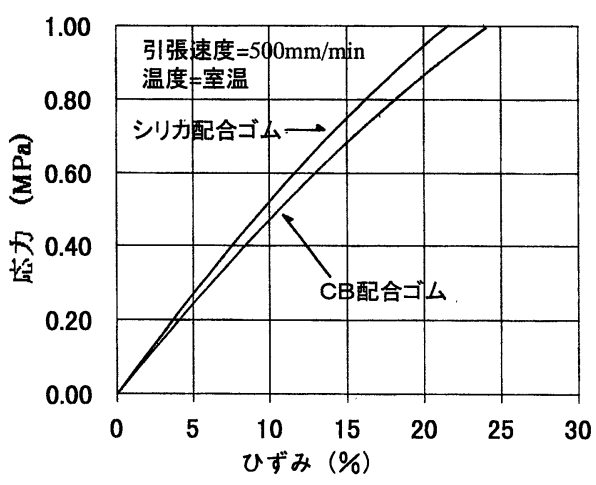

図 $3 \mathrm{~S}-\mathrm{S}$ 曲線

小さく，かつ前記した $50^{\circ} \mathrm{C} \tan \delta(15$ $\mathrm{Hz}$ )が小さいことが式(1)より低燃費性の 原因であると考察した. また, シリカ配 合で数種 SBRの S-S 曲線を比較した結 果，ひずみの小さい部分はほぼ一致し た.これら 2.1) 2.3)の結果から, シ リ力配合でのみ各種 SBRの安全性，燃 費性を比較する場合は, CB 配合のラボ 指標と同一のものを用いることが可能で あると考察した。

\section{3 . シリカ配合での各種 SBR の評価 ${ }^{6)}$}

シリカ配合の安全性と燃費性のラボ指標とし て，使用可能と判断した CB 配合のそれと同じラ ボ指標を用い, トレッドのシリカ配合での燃費 性, 安全性に対する SBR ミクロ構造と変性剂等 の影響について検討した。使用したSBRの分析 結果を表 3 に示す.

\section{1 シリカ配合での燃費性への影響因子}

$\mathrm{Tg}$ が低いほど $50^{\circ} \mathrm{C} \tan \delta$ は小さく，また Tg 同等の場合 $\mathrm{ST}$ 量が少ないか, 又はビニル量が多 いほど $50^{\circ} \mathrm{C} \tan \delta$ は小く, かつこれらミクロ構 造の $50^{\circ} \mathrm{C} \tan \delta に$ 対する影響は $\mathrm{Tg}$ の影響より強 いことが分かった. また，変性剤の $50^{\circ} \mathrm{C} \tan \delta に$ 対する影響はみられなかった，更にミク口構造の $50^{\circ} \mathrm{C} \tan \delta に$ 対する影響をバウンドラバー測定に より検討を行った. 図 4 にビニル量とバウンドラ バー量の関係を, 図 5 にバウンドラバー量と $50^{\circ} \mathrm{C} \tan \delta$ の関係を示す。これより，ビニル量が 増えるとバウンドラバー量が増し, $50^{\circ} \mathrm{C} \tan \delta$ が 下がることが分かった。つまり，ビニルはシリカ 又は Si 69 と比較的強いインターラクションをも
表 $3 \mathrm{SBR}$ の分子特性

\begin{tabular}{lcccc} 
変性剂 & $\begin{array}{c}\text { ビニル量 } \\
(\%)\end{array}$ & $\begin{array}{c}\text { スレン量 } \\
(\%)\end{array}$ & $\begin{array}{c}\mathrm{Tg} \\
\left({ }^{\circ} \mathrm{C}\right)\end{array}$ & $\begin{array}{c}\mathrm{Raw} \mathrm{MV} \\
\left(1+4,100^{\circ} \mathrm{C}\right)\end{array}$ \\
$\mathrm{SnCl}_{4}$ & 62 & 20 & -36 & 74.0 \\
$\mathrm{SnCl}_{4}$ & 21 & 35 & -51 & 74.0 \\
$\mathrm{Ar}-(\mathrm{NCO}) \mathrm{n}$ & 18 & 30 & -63 & 48.0 \\
$\mathrm{TFAS}_{\mathrm{SiCl}}$ & 44 & 35 & -35 & 47.0 \\
$\mathrm{TFAS}_{\mathrm{SnCl}}$ & 44 & 35 & -30 & 50.0 \\
$\mathrm{SnCl}_{4}$ & 43 & 36 & -23 & 41.0 \\
$\mathrm{SnCl}_{4}$ & 32 & 5 & -79 & 60.0 \\
$\mathrm{TFAS}_{\mathrm{SnCl}}$ & 45 & 10 & -64 & 73.0 \\
$\mathrm{ABP}$ & 57 & 15 & -48 & 61.0 \\
None & 62 & 20 & -36 & 42.0 \\
None & 39 & 24 & -55 & 55.0 \\
None & 69 & 20 & -32 & 45.0 \\
& 13 & 25 & -56 & 55.0 \\
& 18 & 25 & -71 & 56.0 \\
\hline
\end{tabular}

$\mathrm{Ar}-(\mathrm{NCO}) \mathrm{n}$ : イソシアネート化合物

ABP : 4, 4'-ビス(ジエチルアミノ)ベンゾフェノン

TFAS : トリアルコキシシラン

つためバウンドラバー量が増え，そのため $50^{\circ} \mathrm{C}$ $\tan \delta$ が小さくなると推測した。 また，図 5 より 連続溶液重合 SBR (SBR-14) と E-SBR（\# 1500)

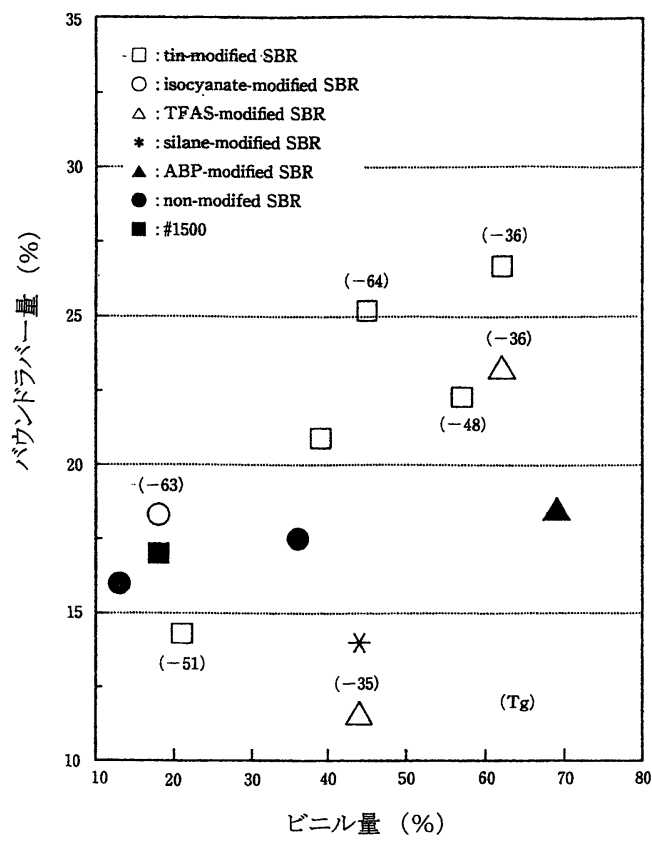

図 4 ビニル量とバウンドラバー量の関係 
表 4 生ゴムムーニ一粘度と配合ゴムムーニ一粘度の関係

\begin{tabular}{lcccccc}
\hline & $\mathrm{SBR}-1$ & $\mathrm{SBR}-3$ & $\mathrm{SBR}-5$ & $\mathrm{SBR}-10$ & $\mathrm{SBR}-12$ & $\# 1500$ \\
\hline 変性剤 & $\mathrm{SnCl}_{4}$ & $\mathrm{Ar}^{-}(\mathrm{NCO}) \mathrm{n}$ & $\mathrm{SiCl}_{4}$ & $\mathrm{TFAS}$ & $\mathrm{None}$ & None \\
生ゴムムーニー粘度 & 74.0 & 48.0 & 50.0 & 42.0 & 55.0 & 52.0 \\
配合ゴムムー二ー粘度 & 74.0 & 76.5 & 88.0 & 76.0 & 63.0 & 74.5 \\
\hline
\end{tabular}

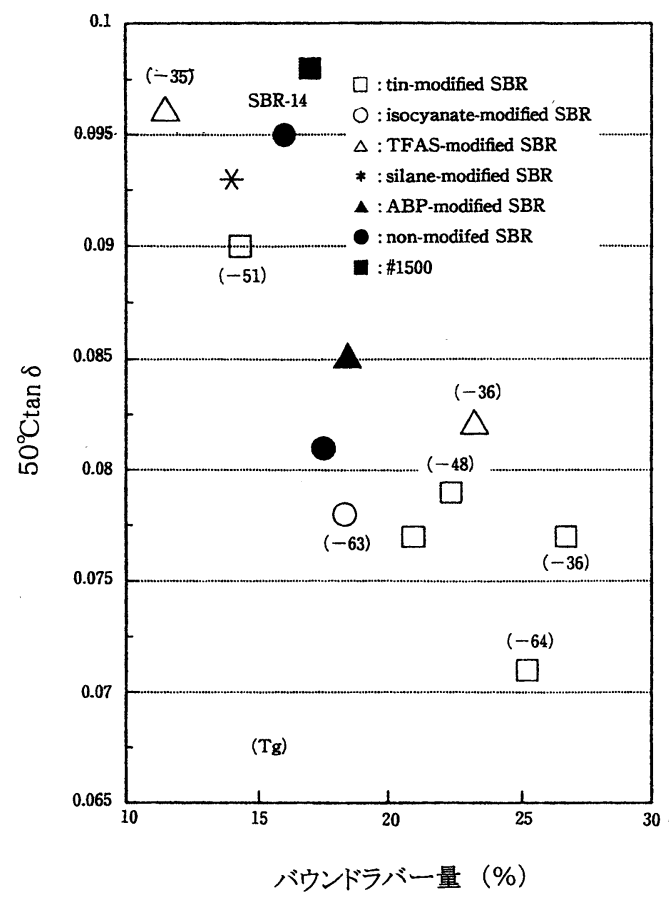

図 5 バウンドラバー量と $50^{\circ} \mathrm{C} \tan \delta$ の関係

の $50^{\circ} \mathrm{C} \tan \delta$ は, 同じ ST 量のバッチ溶液重合 SBR (SBR- 1 〜 13)のそれと比較して高い.これ は，連続溶液重合 SBR $\mathrm{E}-\mathrm{SBR}$ は，バッチ溶 液重合 SBR と比較して分子量分布が広く低分子 量成分が多いためと推測した。

\section{2 シリカ配合での安全性への影響因子}

$0^{\circ} \mathrm{C} \tan \delta$ は， $\mathrm{Tg}$ に依存しているが，変性剂の 影響はみられなかった。

これらの結果から，CB 配合と大きく異なる点 として，変性剤のこれら加硫物性等に対する影響
はみられなかったが, 表 4 に示すように, Sn 変 性 SBR は他の変性 SBR と比べて, 生ゴムムー ニ一粘度 $(\mathrm{MV})$ に対し配合ゴム MVを上げない 特徵がみられた。 これより, Sn 変性 SBR はシ リカ配合での加工性が良好であることが分かっ た.

\section{4.おわりに}

以上，シリカ配合夕イヤの燃費性と安全性を実 験室で評価するために，これらの性能のラボ指標 の確立を試み，更にSBRの分子特性とこれらの 性能の関係の解明を試みた。

今後， $\mathrm{CB}$ 配合系とシリカ配合系等の異なる配 合系の燃費性, 安全性を比較する場合, 硬度や貯 蔵弾性率などに違いがあることに注意しなければ ならない，すなわち，両フィラー配合系における 燃費性, 安全性を比較するには, 粘弾性データー と共に硬度や弾性率などを合わせて検討すること が必要であると考えられる。

最後に共同研究者各位に謝辞を述べるととも に，日本ゴム協会から優秀論文賞を授与していた だいたことに対して, 心から感謝の意を表しま す.

\section{引用 文 献}

1 ）例之ば堤文雄, 榊原満彦, 大島 昇：日ゴム協誌, 63, 243(1990)

2) Saito, Y.: Kautsch. Gummi. Kunstst, 39, 30 (1986)

3) Wolff, S. : TyreTech'93, Paper 13(1993)

4 ）牧浦雅仁：日ゴム協誌，71，583(1998)

5 ) 小林直一, 古田 勲, 明間 博, 五十野善信 : 1999 年ゴム協年次大会講演要旨, p.4 (1999)

6) 小林直一, 古田 勲：日ゴム協誌, 70, 147 (1997)

7 ）二宮和彦，前川悦治：日ゴム協誌，39，595(1966) 